\title{
Skiing and Snowboarding in Switzerland: Trends in Injury and Fatality Rates Over Time
}

\author{
Giannina Bianchi, Othmar Brügger, and Steffen Niemann
}

\begin{abstract}
Introduction: Skiing and snowboarding are two of the most popular sports in Switzerland, but their popularity means that the absolute number of injuries remains high. To plan and evaluate effective injury prevention, detailed insights into the injuries that occur are needed. Objective: The aim of this study was to characterize the current status (average winter season 2008-2012) and trends in injury rate (between 2005 and 2012) and fatality rate (between 2000 and 2014) among skiers and snowboarders in Switzerland. Materials/Methods: Injury data from different sources were collected and analyzed. Extrapolation and estimates were made based on a special household survey and insurance data. All fatal injuries were recorded in a separate database. Moreover, an annual survey on Swiss slopes was conducted that delivered different information about skiers and snowboarders in these areas. Skier days were collected by the Swiss Cableways. Results: The rate of sustaining an injury while skiing or snowboarding on Swiss slopes was 2.8 per 1000 skier days on average from 2008 to 2010 . The fatality rate was 0.7 deaths per one million skier days in the same period of time. The injury rate remained relatively stable between 2005 and 2012, and the fatality rate has not changed since 2000. Discussion: Compared with other countries, the rates of injury or even fatality while skiing or snowboarding falls in the mid-range for Switzerland; however, further prevention efforts targeting behavior and conditions are needed to minimize and even reduce injuries.
\end{abstract}

Keywords Skiing $\bullet$ Snowboarding $\bullet$ Injury rate $\bullet$ Epidemiology

\section{Introduction}

Skiing and snowboarding are two of the most popular sports in Switzerland. Each year, some 2.5 million Swiss residents take to the slopes at least occasionally on skis and another 370,000 on snowboards [1]. Moreover, ski tourism in Switzerland attracts many visitors from other countries. Around a quarter of skiers and

G. Bianchi $(\varangle) \bullet$ O. Brügger $\bullet$ S. Niemann

bfu-Swiss Council for Accident Prevention, Hodlerstrasse 5a, CH-3011 Berne, Switzerland

e-mail: forschung@bfu.ch 
snowboarders on Swiss slopes are from outside of Switzerland [1]. In 2013, 35\% of Swiss adults (15-74 years) and 53\% of Swiss children (10-14 years) skied [2, 3] and the proportion of active skiers in the Swiss population rose between 2007 and 2013 by 9 (adults, 15-74 years) and 12 (children, 10-14 years) percentage points. The proportion of active snowboarders however, has remained more stable between 2007 and 2013 (adult change: 0 percentage points, children: + 1 percentage point) and in $2013,5 \%$ of Swiss adults and $13 \%$ of Swiss children were snowboarding at least occasionally. No change has been observed between 2007 and 2013 for the days per year or time per day skiers and snowboarders spend on the slopes. Nevertheless, skier days, which are a good measure of the skiers and snowboarders using a resort, have declined slightly in Swiss ski resorts in recent years [4, 5] (Fig. 1). One skier day is generated when one person visits a ski area for the purpose of skiing, snowboarding, or other downhill activity, regardless of the visit duration. The popularity of snow sports in Switzerland means that absolute numbers of injuries remains high. From a 5-year average for 2008-2012, estimated 51,000 skiers and 15,000 snowboarders who reside in Switzerland sustained injuries serious enough to require medical attention [6] (Table 1). However, to identify the full extent of injuries on Swiss slopes, the injuries of visitors from other countries must be taken into account as well. Moreover, injury rate needs to be calculated to track

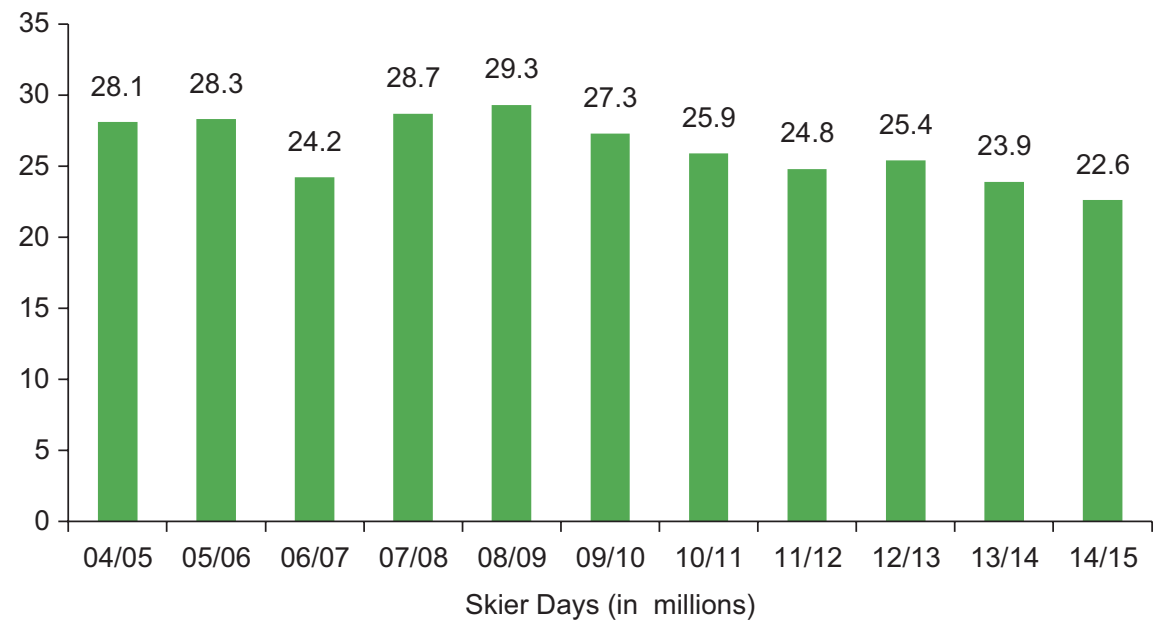

Fig. 1 Trend for skier days in Swiss ski resorts registered by Swiss aerial cableways (SBS), winter season 2004/05-2014/15

Table 1 Absolute numbers of injured skiers and snowboarders (all Swiss residents) on slopes in Switzerland and other countries per year in 2005-2012 and Ø 2008-2012

\begin{tabular}{l|l|l|l|l|l|l|l|l|l}
\hline Sport & 2005 & 2006 & 2007 & 2008 & 2009 & 2010 & 2011 & 2012 & $\emptyset 2008-2012$ \\
\hline Skiing & 48,030 & 49,650 & 45,090 & 52,550 & 52,960 & 50,460 & 47,490 & 50,600 & 50,812 \\
\hline Snowboarding & 15,160 & 14,980 & 15,060 & 15,060 & 15,550 & 13,920 & 14,450 & 14,070 & 14,610 \\
\hline Total & 63,190 & 64,630 & 60,150 & 67,610 & 68,510 & 64,380 & 61,940 & 64,670 & 65,422 \\
\hline
\end{tabular}


trends and compare it with the injury rate associated with other sports and other countries. Detailed insights into the injuries that occur are the basis for planning and evaluating effective injury prevention.

\section{Objective}

The aim of this study was to portray the current status (average winter season 2008-2012) and trends in injury rate (between 2005 and 2012) and fatality rate (between 2000 and 2014) among snow skiers and snowboarders in Switzerland.

\section{Materials and Methods}

Snow sport injuries have been recorded in Switzerland in a variety of injury databases, in some cases for as long as 30 years. However, no data covering all population groups or the whole of Switzerland are available for the sports sector, and estimates must be used. The estimated absolute number of injuries sustained by Swiss residents while skiing and snowboarding on slopes in and outside of Switzerland has served as a basis for the present calculations [6] (Table 1). Primarily, the data for the estimation were acquired in a special survey of 15,000 Swiss households using computer-assisted telephone interviews [7]. This calculation is not part of the current study and can be accessed in the corresponding report [7].

To calculate the full extent of injuries in Swiss ski resorts, several assumptions based on different data bases were required. Data from the Central Office for Statistics under the Federal Law for Accident Insurance enable determination of the proportion of injuries that Swiss residents sustain on slopes outside of Switzerland [6]. This information contains data on injuries sustained by around four million employed people (approximately $50 \%$ of the Swiss population). However, data are missing for some population groups such as children, students, senior citizens, those who are not employed, or visitors from other countries. Therefore, the database described in the following was also consulted. To evaluate personal protective equipment used in winter sports (helmet, wrist protector, back protector), a sample survey is conducted every year on different runs in 21 snow sport resorts, and demographic information like age, gender, type of sport, and country of residence is collected as well [8]. Since winter 2002/03, more than 5000 skiers and snowboarders have been randomly selected and surveyed annually. This survey allows estimation of the proportion of skiers and snowboarders as well as Swiss residents and visitors from other countries on Swiss slopes. Moreover, a full survey of all fatal sports accidents has been recorded in a separate database since $2000[9,10]$. These data include all fatalities that have occurred during sporting activities (excluding road traffic accidents) if the victims died as a result of the injury either at the site or within 30 days of the accident. Due to the variety of variables tracked, these data give insight into skiing and snowboarding fatalities and allow for their detailed analysis. 
The absolute number of injuries differs from year to year depending on different factors, e.g., snow conditions, weather, holidays, or economics. Therefore, a 5-year average of the newest data available (2008-2012) was used to show the current injury situation in Swiss ski resorts. To communicate the injury rate with winter sport and to compare it in an international context, two units of measurement were used: number of injured skiers or snowboarders per 1000 skier days (or skier visits) and mean days between injuries (MDBI), or the average of skier days between two injury events. The higher the MDBI value, the lower the rate of injury. The different steps in the calculation are shown with the 5-year average. The results are presented in absolute injury numbers and injury rates, and 95\% confidence intervals (CI) are also presented.

\section{Results}

In a 5-year average for 2008-2012, a projected 51,000 skiers and 15,000 snowboarders who reside in Switzerland annually sustain injuries serious enough to require medical attention [6] (Table 1). During these 5 years, 14\% (95\% CI $0.13-$ 0.14 ) of skiers and $8 \%$ (95\% CI 0.08-0.09) of snowboarders represented in the statistics sustained an injury on slopes outside of Switzerland. Consequently, on Swiss slopes, an average of 44,000 skiers and 14,000 snowboarders residing in Switzerland sustain injuries (Table 2). Visitors from other countries also suffer injuries while skiing and snowboarding in Switzerland, and the frequency for these foreign guests on Swiss slopes barely differs from those for Swiss residents [11]. The representative annual survey on Swiss slopes shows that 27\% (95\% CI $0.21-$ 0.32 ) of skiers and $20 \%$ (95\% CI $0.16-0.25)$ of snowboarders are visitors from foreign countries. Overall, taking the 5-year average for 2008-2012, annually 60,000 skiers and 17,000 snowboarders on Swiss slopes are injured seriously enough to require medical attention.

In the same period, the Swiss aerial cableways registered an average of 27.2 million skier days [4, 5] (Fig. 1). Thus, the rate of injury for 2008-2012 on Swiss slopes was on average 2.8 injuries per 1000 skier days (95\% CI 2.79-2.83) or 355 (95\% CI 353-358) MDBI. Assuming that the distribution of skiers and snowboarders on Swiss slopes can be translated to the distribution of skier days for these two sports, $80 \%$ (95\% CI $0.77-0.82$ ) of skier days are generated by skiers and $20 \%$ (95\% CI

Table 2 Absolute number of injured skiers and snowboarders on slopes in Switzerland according to sport and country of resident, $\varnothing$ 2008-2012

\begin{tabular}{|c|c|c|c|c|c|c|}
\hline \multirow[b]{2}{*}{ Country of resident } & \multicolumn{2}{|l|}{ Skiing } & \multicolumn{2}{|c|}{ Snowboarding } & \multicolumn{2}{|l|}{ Total } \\
\hline & Number & Share, \% & Number & Share, \% & Number & Share, \% \\
\hline Swiss residents & 44,000 & 73 & 14,000 & 80 & 58,000 & 75 \\
\hline Foreign visitors & 16,000 & 27 & 3000 & 20 & 19,000 & 25 \\
\hline Total & 60,000 & 100 & 17,000 & 100 & 77,000 & 100 \\
\hline
\end{tabular}


0.18-0.23) by snowboarders [12]. Therefore, people skiing in Switzerland sustained 2.8 injuries per 1000 skier days (95\% CI 2.74-2.78) or 363 MDBI (95\% CI 360366), whereas snowboarders experienced 3.0 injuries per 1000 skier days (95\% CI 2.99-3.08) or 330 (95\% CI 325-335) MDBI. Assuming that the proportion of foreign visitors on Swiss slopes remained the same between 2005 and 2012, the risk stayed almost unchanged over these 8 years (Fig. 2).

According to the statistics for fatal sports accidents, for 2008-2012, every year 19 people on average died while skiing or snowboarding. Of these, 8 out of 14 fatal ski accidents as well as four out of five fatal snowboarding accidents occurred outside of the marked and protected slopes while freeriding. With regard to skier days, in this 5-year period (2008-2012), the fatality rate was 0.7 deaths per one million skier days (95\% CI 0.38-1.01) (0.7 for skiers (95\% CI 0.31-0.98) and 0.9 for snowboarders (95\% CI 0.11-1.69)). The absolute risk of sustaining a fatal snow sport injury remained about the same between 2000 and 2014 (Fig. 3).

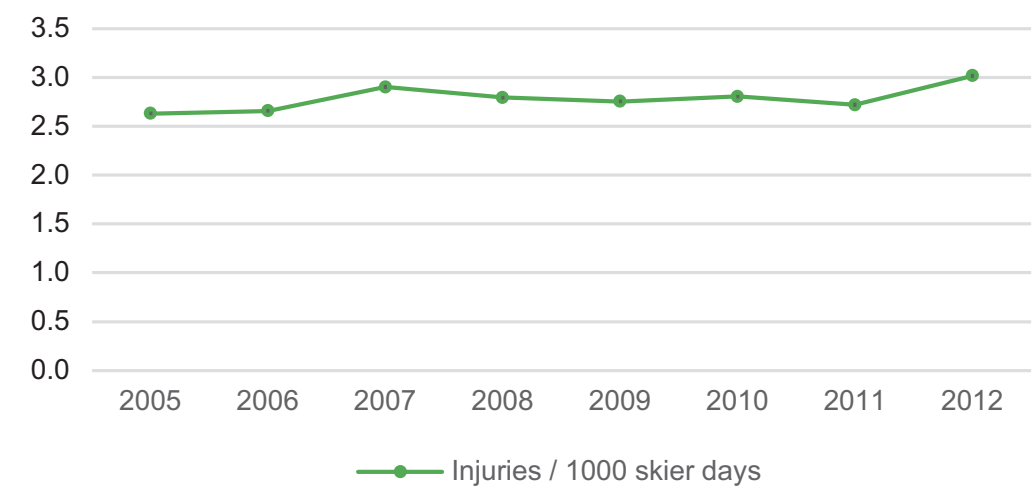

Fig. 2 Trend for non-fatal injury rate while skiing and snowboarding in Switzerland (95\% confidence interval, standard deviation $\pm 0.02-0.04$ ), 2005-2012

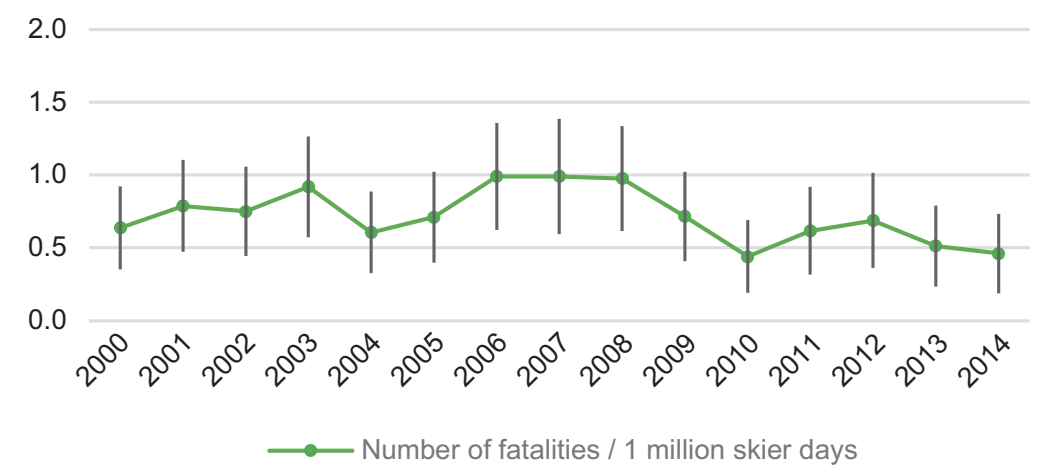

Fig. 3 Trend for fatal injury rate while skiing and snowboarding in Switzerland (95\% confidence interval), 2000-2014 
In relation to the 60,000 skiers and 17,000 snowboarders injured annually, the case fatality on Swiss slopes was 2.3 fatalities per 10,000 injuries for skiers (95\% CI 1.12-3.57) and 3.0 deaths per 10,000 injuries for snowboarders (95\% CI 0.37-5.59) (2.5 fatalities per 10,000 skiing and snowboarding injuries (95\% CI 1.37-3.60)).

\section{Discussion}

Snow sports are constantly evolving. Over the years, new equipment has been introduced and transport facilities and slope preparation and maintenance continuously modernized. It is, however, not always clear what effect the different factors have had on the risk and severity of various injuries. According to the Swiss aerial cableways, the rate of skier visits shows a declining trend $[4,5]$, but Swiss residents do not seem to have skied or snowboarded less in recent years [2,3]. Hence, the declining trend seems to be due to the diminishing number of foreign visitors, not least because of the high cost of the Swiss currency. Moreover, Swiss residents might also ski and snowboard more often in other countries because of the lower costs.

The injury rate on Swiss slopes ranks in the mid-range compared with the incidence per skier days of skiing and snowboarding injuries published by other countries in recent years (Table 3 ). Studies comparing skiing and snowboarding

Table 3 Comparison of injury rate on slopes in different countries

\begin{tabular}{|c|c|c|c|}
\hline Country & $\begin{array}{l}\text { Winter } \\
\text { season } \\
\text { or year }\end{array}$ & $\begin{array}{l}\text { Injury/1000 } \\
\text { skier days }\end{array}$ & Database \\
\hline Switzerland & $2008-2012$ & 2.8 & $\begin{array}{l}\text { Extrapolation of injuries according to } \\
\text { different sources }\end{array}$ \\
\hline $\begin{array}{l}\text { Austria, Ruedl et al. } \\
\text { [17] }\end{array}$ & $2012 / 13$ & 0.6 & $\begin{array}{l}\text { Injuries collected in questionnaires by } \\
\text { rescue personnel on ski slopes and } \\
\text { physicians in the hospital or their practices }\end{array}$ \\
\hline $\begin{array}{l}\text { Norway, Ekeland and } \\
\text { Rødven (2015) [18] }\end{array}$ & $2012 / 13$ & 1.3 & Ski patrol-reported injuries \\
\hline $\begin{array}{l}\text { Greece, Zacharopoulos } \\
\text { et al. [19] }\end{array}$ & $2005 / 06$ & 6.1 & $\begin{array}{l}\text { Case-control study at two major ski } \\
\text { resorts; medical station-reported injuries }\end{array}$ \\
\hline $\begin{array}{l}\text { Greece, Zacharopoulos } \\
\text { et al [20] }\end{array}$ & $2007-2013$ & 4.1 & $\begin{array}{l}\text { Case-control study at two major ski } \\
\text { resorts; medical station-reported injuries }\end{array}$ \\
\hline $\begin{array}{l}\text { France, Médecins de } \\
\text { Montagne [13] }\end{array}$ & $2012 / 13$ & 2.6 & $\begin{array}{l}\text { Injuries recorded by } 47 \text { medical doctors } \\
\text { based in ski resorts }\end{array}$ \\
\hline $\begin{array}{l}\text { France, Médecins de } \\
\text { Montagne [14] }\end{array}$ & $2014 / 15$ & 2.5 & $\begin{array}{l}\text { Injuries recorded by } 47 \text { medical doctors } \\
\text { based in ski resorts }\end{array}$ \\
\hline $\begin{array}{l}\text { United States, Shealy } \\
\text { et al. [15] }\end{array}$ & 2010 & $\begin{array}{l}\text { Ski: } 2.5 \text {, } \\
\text { Snowboard: } \\
6.1\end{array}$ & $\begin{array}{l}\text { Injuries recorded directly or through } \\
\text { insurance companies in all ski areas in } \\
\text { the United States }\end{array}$ \\
\hline $\begin{array}{l}\text { United States, Johnson } \\
\text { et al. [21] }\end{array}$ & 2010 & Ski: 1.9 & $\begin{array}{l}\text { Injuries presenting to an injury clinic at } \\
\text { one medium-sized ski area }\end{array}$ \\
\hline $\begin{array}{l}\text { United States, Kim } \\
\text { et al. [16] }\end{array}$ & $2005 / 06$ & $\begin{array}{l}\text { Snowboard: } \\
\sim 3\end{array}$ & $\begin{array}{l}\text { Injuries presenting to an injury clinic at } \\
\text { one medium-sized ski area }\end{array}$ \\
\hline
\end{tabular}


injuries all find a higher injury risk for snowboarders compared to skiers [13-16]. The lowest rate has been reported in two studies from Austria (0.6 injuries/1000 skier days) [17] and Norway (1.3 injuries/1000 skier days) [18], both made in winter 2012/13. The highest published injury rate was observed in Greece in winter 2005/06 (6.1 injuries per 1000 skier days) [19]. However, the injury rate during the period 2007-2013 was still 4.1 injuries per 1000 skier days [20]. In France, the injury rate has been reported to be almost the same as in Switzerland, with snow sport participants sustaining 2.6 injuries per 1000 skier days in winter 2012/13 (ski: 2.5, snowboard: 2.9) [13]. Newer data from France, however, show an even lower rate of 2.5 injuries per 1000 skier days (winter 2014/15) [14]. In the United States in winter 2010, the injury rate for skiers was also lower than in Switzerland (2.5 injuries/1000 visits), but the rate for snowboarders sustaining an injury on slopes in the United States was 6.1 injuries per 1000 visits, much higher than in Switzerland [15]. In comparison, another US study using injury reports from one medium-sized northern ski area found an overall injury rate of only 1.9 injuries per 1000 skier visits (excluding snowboarders) for 2010 [21]. In addition, snowboard injuries at the same ski area analyzed in another study showed a much lower incidence than that calculated for the United States overall [16]. In that study, in one 5-year period (2001/02-2005/06), the risk for sustaining a snowboard injury was lower than $300 \mathrm{MDBI}$, which corresponds to around three injuries per 1000 skier days.

Data collection and analysis methods vary among countries. Some calculations are based on ski patrol reports [18], others on information gained from physicians in hospitals or doctors based in ski resorts [13,14, 16, 19-21], and other on combinations of different methods of data collection $[15,17]$. Therefore, it is difficult to compare the injury incidence among the various countries. One review article addressing snowboarding injuries has illustrated the wide range of injury rate due to different databases and years; the authors found injury rates ranging from 0.8 to 8.0 per 1000 snowboarder days [22].

In Switzerland, no clear change can be identified in the development of overall rate (Figs. 2 and 3). Injuries have remained relatively stable between 2005 and 2012. A similar observation can be made for Norway between 1996 and 2012, where the injury rate varied between 1.2 and 1.5 injuries per 1000 skier days [18, 23]. In France, the rate for sustaining an injury has remained the same over a long period of time (1992-2014), and the skiing injury rate has increased and decreased only little over more than 20 years $[14,24]$. However, a slightly growing rate of injury was observed for snowboarders between 1992 and 2005 (from 2.6 to 2.7 injuries per 1000 skier days), followed by a subsequent reversal trend with the lowest rate of 2.4 injuries/1000 skier days in 2010. Studies from the United States demonstrate an increase in injury rate for snowboarders since the turn of the millennium, whereas the risk of sustaining an injury while skiing decreased over the years [16]. Another US study calculated a decrease of 55\% in injury rate while skiing, down to 1.9 injuries per 1000 skier visits since the 1970s [25]. In Austria, a decline in overall snow sports injury rate was observed for skiers and snowboarders: the risk of sustaining an injury dropped from 1.4 in 1997/98 to 1.3 injuries per 1000 skier days in 2002/03 [26]. Moreover, another Austrian study showed a further decline to 0.6 injuries/1000 
skier days up to 2012/13 [17]. It seems that in many regions, the overall risk of sustaining a snow sport injury has remained the same or even dropped through the years. It can be assumed that snow sports have been made safer, especially from the 1970s to the 1990s, when the injury risk was halved [27]. Relating to the data of various other countries, it can be speculated that the risk of skiing injury decreased while the risk of a snowboarding injury slightly increased.

According to calculations from the Observatory Sport and Physical Activity Switzerland, the Swiss population experienced some 35 medically treated injuries per 100,000 h of skiing activity and 77 injuries per 100,000 h of snowboarding activity [28]. To compare, the highest estimated rate in that study was 193 injuries per $100,000 \mathrm{~h}$ of playing soccer, and the lowest was 3 per 100,000 $\mathrm{h}$ of practicing fitness, aerobic, or gymnastics. Hence, across all types of sport, the injury rate in snow sports ranks in the mid-range. Although the exposure-related injury rate is quite low in comparison to other types of sport, the popularity of snow sports in Switzerland means that the absolute number of injuries remains high.

In Switzerland, the rate of sustaining a fatal snow sport injury has changed little since the turn of millennium (Fig. 2). In those 15 years, only a few studies have been published showing the fatality rate while skiing or snowboarding on slopes. In the United States, different studies by the same research group have relied on several databases [29-31]. In 2006, these authors published their newest study, which took into account different sources and therefore gives the best overall view [31]. On average, of the 14 winter seasons included in their study (1991/92-2004/05), the overall death rate was 0.7 death per million skier visits and thus similar to the rate on Swiss slopes. In contrast to the data generated in Switzerland, the incidence rate of fatalities in skiing ( 0.8 deaths per million skier visits) remains greater than for snowboarding ( 0.5 deaths per million skier visits). In accordance with the Swiss data, no evidence suggests that the fatality rates for snowboarding or skiing have changed significantly over the years. However, no data from this database are available for the United States since 2004/05. According to US data collected by the National Ski Areas Association (NSAA), the fatality rate in the winter $2014 / 15$ was 0.7 per million skier visits [32]. In a 5 -year average, 0.7 deaths occurred per one million skier visits, which is comparable with the data from Switzerland. Moreover, no increase or decrease in the NSAA data emerged in the study period.

In Austria, the reported average is 0.4 skier and snowboarder fatalities per million skier days, resulting from trauma (i.e., fall, collision, impact, avalanche on the slopes) [33]. In contrast to the studies from Switzerland and the United States, the Austrian study excluded fatalities happening off-piste. In Switzerland, almost two thirds of skiing and snowboarding fatalities have occurred outside marked and secured slopes. Moreover, the Austrian study showed that another 0.4 deaths per million skier days resulted from non-trauma-related (primarily cardiac arrest) incidents. Non-traumatic events are not included in the Swiss database of fatal sports accidents. Even if the rates are not directly comparable because different databases were used, however, the rates of fatal ski and snowboard accidents among the different countries are similar. 


\section{Study Limitations}

Snow sport injuries have been recorded in Switzerland in a variety of injury databases. However, no data covering all population groups or the whole of Switzerland are available for the sports sector, so estimates must be used. Moreover, some data (e.g., proportion of visitors from other countries) are not available for every year individually forcing the assumption that the proportion remains the same over different winter seasons. This study was not designed to address data quality, per se, however, quality assurance measures to uncover inconsistencies and other anomalies in the data were consistently applied. Although the data quality was checked in many areas, bias cannot be ruled out. Future research is planned to evaluate the data validity more precisely.

\section{Conclusion}

The rate of sustaining an injury while skiing or snowboarding on Swiss slopes was 2.8 per 1000 skier days on average from 2008 to 2010 . The fatality rate in the same period was 0.7 deaths per one million skier days. Injury rates have remained relatively stable between 2005 and 2012, and fatality rate has not shifted since the turn of the millennium. Compared with other countries, in Switzerland, the rates of injury and fatality ranks in the mid-range. Even if the exposure-related injury rate is quite low in comparison to other types of sports, the popularity of snow sports in Switzerland means that the absolute number of injuries remains high. Further prevention efforts targeting behavior (e.g., the wearing of personal protective equipment) and conditions (e.g., the safer construction of snow parks) are needed to minimize or even reduce these numbers [34].

\section{References}

1. Bianchi G, Brügger O (2016) [Injuries in skiing and snowboarding in Switzerland: accident situation, risk estimation and development], summary in English. bfu-Swiss Council for Accident Prevention. http://www.bfu.ch/de/bestellen/alles?k=2.286. Accessed 12 Dec 2016

2. Lamprecht M, Fischer A, Stamm H (2014) [Sport in Switzerland 2014: sport behaviour in the Swiss Population]. Swiss Federal Office for Sport (FOSPO). http://www.sportobs.ch/fileadmin/sportobs-dateien/Downloads/Sport_Schweiz_2014_d.pdf. Accessed 12 Jan 2016

3. Lamprecht M, Fischer A, Stamm H (2014) [Sport in Switzerland 2014: report on children and adolescents]. Swiss Federal Office for Sport (FOSPO). http://www.sportobs.ch/fileadmin/sportobs-dateien/Downloads/2014_Kinder_Jugendbericht_d_screen.pdf. Accessed 12 Jan 2016

4. Vanat L (2015) 2014 International report on snow \& mountain tourism: overview of the key industry figures for ski resorts. www.vanat.ch/RM-world-report-2014.pdf. Accessed 12 Jan 2016

5. Vanat L (2015) Saisonbilanz winter 2014/15-Entwicklungen. Erkenntnisse und Prognosen. Swiss Cableways (SBS). http://vanat.ch/RM-CH-palmares-JS2015-R-D-Laurent\%20Vanat. pdf. Accessed 12 Jan 2016 
6. bfu-Swiss Council for Accident Prevention (2015) STATUS 2015 statistics on nonoccupational accidents and the level of safety in Switzerland. bfu. http://www.bfu.ch/de/ bestellen/alles?k=2.265. Accessed 12 Jan 2016

7. Niemann S, Lieb C, Sommer H (2015) [Non-occupational accidents in Switzerland: updated extrapolation and cost calculation]; condensed version in English. bfu-Swiss Council for Accident Prevention. http://www.bfu.ch/de/bestellen/alles?k=2.246. Accessed 12 Jan 2016

8. bfu-Swiss Council for Accident Prevention (2015) bfu survey 2015: use of protective equipment in skiing and snowboarding. bfu. www.bfu.ch/de/bestellen/alles?k=2.999. Accessed 12 Jan 2016

9. Bianchi G (2015) bfu-survey 2015: fatal sports accidents in Switzerland 2000-2014. bfuSwiss Council for Accident Prevention. www.bfu.ch/de/bestellen/alles?k=2.999. Accessed 16 Jan 2016

10. Bianchi G, Brügger O (2013) [bfu statistics on fatal sports accidents in Switzerland, 20002012]. bfu-Swiss Council for Accident Prevention. http://www.bfu.ch/de/bestellen/ alles?k=2.117. Accessed 12 Jan 2016

11. Fuchs B, Gmünder C, Brügger O et al. (2005) [Individual protective gear in snow sport: survey of wearer behaviour and reasons for wearing], summary in English. bfu-Swiss Council for Accident Prevention. http://www.bfu.ch/de/bestellen/alles?k=2.999. Accessed 12 Jan 2016

12. bfu-Swiss Council for Accident Prevention (2015) bfu-survey 2015: use of protective equipment in skiing and snowboarding, special analysis (unpublished). bfu, Berne

13. Médecins de Montagne (2013) L'accidentologie des sports d'hiver: Hiver 2012-2013, Dossier de Presse. Accidentologie des sports d'hiver. http://www.mdem.org. Accessed 22 Sept 2014

14. Médecins de Montagne (2015) L'accidentologie des sports d'hiver: Hiver 2014-2015, Dossier de Presse. Accidentologie des sports d'hiver. http://www.mdem.org. Accessed 11 Jan 2016

15. Shealy JE, Ettlinger CF, Scher I et al (2015) 2010/2011 NSAA 10-year interval injury study. J ASTM Int 20:93-111. doi:10.1520/STP158220140002

16. Kim S, Endres NK, Johnson RJ et al (2012) Snowboarding injuries: trends over time and comparisons with alpine skiing injuries. Am J Sport Med 40(4):770-776. doi:10.1177/ 0363546511433279

17. Ruedl G, Philippe M, Sommersacher R et al (2014) Current incidence of accidents on Austrian ski slopes. Sportverl Sportschad 28(4):183-187. doi:10.1055/s-0034-1385244

18. Ekeland A, Rødven A (2015) A injury trends in Norwegian ski resorts during the 16 years period 1996-2012. In: Petrone N, Marcolin G (eds) Book of abstract: 21st international congress on Ski trauma and skiing safety, International Society for Skiing Safety, San Vito di Cadore, 8-13 March 2015, p 65

19. Zacharopoulos A, Tzanakakis N, Douka M (2008) Skiing and snowboarding injuries in Greece: a two-year case-control study. J ASTM Int 5(6):23-30. doi:10.1520/STP47462S

20. Zacharopoulos A, Smyrnis A, Vlastos I et al (2015) Skiing injuries in Greece: a six years casecontrol study (2007-2013). J ASTM Int 20:122-140. doi:10.1520/STP158220140006

21. Johnson RJ, Ettlinger CF, Shealy JE (2011) Skier injury trends, 1972 to 2010. In: Scher I, Greenwald R (eds) Book of abstract: 19th International Congress on Ski Trauma and Skiing Safety, Keystone, 1-7 May 2011

22. Russell K, Hagel B, Goulet C (2010) Snowboarding. In: Caine DJ, Harmer PA, Schiff MA (eds) Epidemiology of injuries in olympic sports. Blackwell, Oxford, pp 447-472. doi:10.1002/9781444316872.ch29

23. Ekeland A, Rødven A (2009) Injury trends in Norwegian ski resorts in the 10 year period 1996-2006. J ASTM Int 17:31-38. doi:10.1520/JAO101620

24. Laporte JD, Bajolle L, Lamy D et al (2012) Winter sports injuries in France over two decades. J ASTM Int 19:201-213. doi:10.1520/STP20120055

25. Johnson RJ (2009) Update on injury trends in Alpine Skiing. J ASTM Int 5(10):11-22. doi:10.1520/JAI102046

26. Burtscher M, Gatterer H, Flatz M et al (2008) Effects of modern ski equipment on the overall injury rate and the pattern of injury location in Alpine skiing. Clin J Sport Med 18(4):355-357. doi:10.1097/MJT.0b013e31815fd0fe 
27. Koehle MS, Lloyd-Smith R, Taunton JE (2002) Alpine ski injuries and their prevention. Sports Med 32(12):785-793. doi:10.2165/00007256-200232120-00003

28. Observatory Sport and Physical Activity Switzerland (2015) Indikator 4.1: Niveau und Entwicklung der Sportunfälle und- verletzungen. http://www.sportobs.ch/fileadmin/sportobsdateien/Indikatoren_PDF/IND_4_1.pdf. Accessed 12 Jan 2016

29. Shealy JE, Thomson T (1996) Death in downhill skiing from 1976 trough 1992: a retrospective view. In: Mote CD, Johnson RJ, Hauser W, Schaff PS (eds) Skiing trauma and safety: tenth volume, ASTM STP 1266. American Society for Testing and Materials, West Conshohocken, pp 66-72. doi:10.1520/STP37915S

30. Shealy JE, Ettlinger CF, Johnson RJ (2000) Rates and modalities of death in the U.S.: snowboarding and skiing differences 1991/92 through 1998/99. In: Johnson RJ, Zucco P, Shealy JE (eds) Skiing trauma and safety: thirteenth volume, ASTM STP 1397. American Society for Testing and Materials, West Conshohocken, pp 132-138. doi:10.1520/STP12871S

31. Shealy JE, Johnson RJ, Ettlinger CF (2006) On Piste fatalities in recreational snow sports in the U.S. J ASTM Int 3(5):27-34. doi:10.1520/JAI13893

32. National Ski Areas Association NSAA (2015) Skier/Snowboarder fatality incidents during 2014-15 season. National Ski Areas Acciciation NSAA. http://www.nsaa.org/media/254886/ Fatality_Fact_Sheet_10_15_2015.pdf. Accessed 12 Jan 2016

33. Ruedl G, Bilek H, Ebner H et al (2011) Fatalities on Austrian ski slopes during a 5-year period. Wild Environ Med 22(4):326-328. doi:10.1016/j.wem.2011.06.008

34. Bianchi G, Brügger O (2015) National strategy for preventing injuries from skiing and snowboarding in Switzerland. Schweiz Z Sportmed Sporttrauma 63(2):6-12

Open Access This chapter is distributed under the terms of the Creative Commons AttributionNoncommercial 2.5 License (http://creativecommons.org/licenses/by-nc/2.5/) which permits any noncommercial use, distribution, and reproduction in any medium, provided the original author(s) and source are credited.

The images or other third party material in this chapter are included in the work's Creative Commons license, unless indicated otherwise in the credit line; if such material is not included in the work's Creative Commons license and the respective action is not permitted by statutory regulation, users will need to obtain permission from the license holder to duplicate, adapt or reproduce the material. 